\title{
Can Universities Save Us From Disaster?
}

\author{
Nicholas Maxwell \\ P:ublished in On The Horizon, 2017, Vol. 25 Issue: 2, pp.115-130
}

\begin{abstract}
We face grave global problems. One might think universities are doing all they can to help solve these problems. But universities, in successfully pursuing scientific knowledge and technological know-how in a way that is dissociated from a more fundamental concern with problems of living, have actually made possible the genesis of all our current global problems. Modern science and technology have led to modern industry and agriculture, modern medicine and hygiene, modern armaments, which in turn have led to much that is good, but also to habitat destruction, extinction of species, population growth, the lethal character of modern war, and the impending disasters of climate change. We urgently need to bring about a revolution in universities so that they put problems of living at the heart of the academic enterprise and take, as their basic task, to help humanity learn how to make progress towards as good a world as possible.
\end{abstract}

We are, it seems, confronted by disaster. Grave global problems threaten our future. There is the explosive rise in the world's population. Some estimate that there will be as many as 11 billion people by the end of the century. There is the destruction of natural habitats, the rapid loss of animals in the wild, and the devastating extinction of species. There is massive and, in some respects, growing inequality in wealth and power around the globe. The richest $1 \%$ own over $48 \%$ of the world's wealth, while the poorest half own less that $1 \%$. There is the lethal character of modern war, and our abiding proclivity for war. Whereas around 12 million people died in wars in the 19th century, over 100 million died as a result of war in the 20th century, and we are not doing too well in the 21 st century so far. There is the problem of pollution of earth, sea and air. There is the problem of growing resistance of bacteria to drugs as a result of the misuse of antibiotics. We face the dreadful possibility that we may return to the state of affairs in the 19th century, when trivial infections would lead to death, and diseases such as TB had no effective treatment. And most serious of all, there are the looming disasters of global warming. By the end of the century, large areas of the earth's surface, at present supporting life and agriculture, may become uninhabitable as a result of climate change: drought and rising sea levels.

What makes these threats to our future all the more serious is that they interact with and intensify one another. At a time when the world's population goes up, and more food is required to keep hunger at bay, the capacity of the world to produce food may well go down because of loss of land fit for agriculture due to climate change. Again, as the population increases, the area of the earth's surface capable of supporting human life goes down, due to adverse weather conditions and rising sea levels. Millions of people, in north Africa, parts of Asia and elsewhere, living in areas that increasingly fail to support any kind of human life, will seek to move into neighbouring areas, also degraded and under threat, and so incapable of accommodating refugees. These are circumstances all too likely to provoke war. As global problems intensify, it becomes all the more important that the nations of the earth find ways to cooperate with one another to discover how best to resolve the crises. But as the crises intensify, conditions likely to provoke violent conflict proliferate, and cooperation becomes all 
the more difficult to achieve. It is possible that we now have only a very few decades to put in place measures capable of coming to grips with these grave problems. If we do not do what needs to be done, the world may descend into even greater anarchy and chaos than what we have at present.

If we are to resolve these immense global problems that confront us, we need to learn how to do it. And that in turn means that our institutions of learning - our universities and schools - are well-designed and devoted to the task. What we require, in order to tackle in increasingly effective ways the global problems we face, is community learning, social, economic, institutional and political learning. It is not enough that individuals learn what needs to be done. Communities need to learn. In a sense, the world's population needs to learn - although, because of massive inequalities in wealth and power, some of us carry far heavier a responsibility for the world's problems than others, and some of us are in a far better position to do something about these problems than others are. Only our institutions of learning - our universities and schools - can help promote the kind of community, social, institutional learning that we require. Of course the media, NGOs, charities, pressure groups, can all help. But we need our universities and schools to galvanize the world's population into discovering how to come to grips, effectively, intelligently and humanely, with the world's problems.

Are universities at present organized for and devoted to the task in hand? The answer to this question is deeply shocking. Far from being devoted to helping humanity learn how to tackle our grave global problems, universities are, if anything, in part responsible for the creation of these problems. They are not helping to make things better; on the contrary, they are, in part, responsible for making things worse.

What, we need to ask, is responsible for the genesis of our global problems? Ultimately it is the astonishing intellectual success of modern science and technology. This has, of course, led to much that is of immense benefit. Science and technology have made the modern world possible. But there is a downside. Modern medicine and hygiene have led to population growth. Modern technology has led to modern industry and agriculture which, in turn, have led to destruction of natural habitats, extinction of species, pollution, and global warming. Scientific and technological advance has led to modern armaments, conventional, chemical, biological and nuclear, and so to the lethal character of modern war.

If by the "cause" of an event we mean that prior change which led to the occurrence of the event, and without which the event would not have occurred then, without any doubt, it is the astonishing success of modern science and technology that is the cause of all the global problems indicated above. It is not that we have become more wicked, more stupid, or more selfish. Nor can capitalism be said to be the cause, as some would have it. The old Soviet Union after all was, if anything, even better at creating environmental and other problems as capitalist countries. And capitalism without modern science and technology would have been relatively impotent. In the context of the history of humanity of the last one or two thousand years, what is new, what has dramatically changed, is the advent, and immense intellectual and technical success, of modern science and technology. It is that which has made possible modern industry, agriculture, transport, armaments and medicine, which in turn have led to our current, menacing global problems.

And it is universities that have, by and large, created, nurtured and promoted the science and technology that have, in turn, led to the crises we now face. Universities, instead of helping us learn how to resolve our global problems, are actually a major part of the cause of these problems. 
What on earth has gone wrong? It is after all a major part of the raison d'être of the university that it should help enhance the quality of human life by intellectual, cultural, educational, technological and practical means. But we have just discovered that the university has been behind the genesis of our most serious current global problems - so serious that the future of civilization may even be in doubt.

The problem is this. Universities as at present organized are, when judged from the vital standpoint of helping to promote human welfare, disastrously and damagingly irrational, in a wholesale, structural way, and it is this gross institutional/intellectual irrationality that is responsible for the havoc that universities have caused.

\section{Knowledge-Inquiry}

From the past we have inherited the idea that the proper way for academic inquiry to help promote human welfare is, in the first instance, to acquire knowledge. First, knowledge is to be acquired; then, secondarily, it can be applied to help solve social problems. The intellectual aim of inquiry, of acquiring knowledge is to be sharply distinguished from the social or humanitarian aim of promoting human welfare. In the first instance, academic inquiry seeks to solve problems of knowledge, not social problems of living. Values, politics, expressions of feelings and desires, political philosophies and philosophies of life must all be excluded from the intellectual domain of inquiry to ensure that the pursuit of objective, factual knowledge does not degenerate into mere ideology or propaganda. In order to produce what is of real human value genuine, objective factual knowledge - inquiry must, paradoxically, exclude from the intellectual domain of inquiry all expressions of human problems, suffering and values (although of course factual knowledge about these things can be developed).

At the centre of knowledge-inquiry there is an even more restrictive conception of science. According to this orthodox view, claims to scientific knowledge must be assessed impartially with respect to the evidence, with respect to empirical success and failure. Metaphysical theses - theses which are neither empirically verifiable nor falsifiable, are to be excluded from science. (One form of this idea is Popper's famous demarcation criterion: a theory, in order to be scientific, must be falsifiable.)

I shall call this traditional conception (and kind) of inquiry knowledge-inquiry. By no means everything that goes on in the university today conforms to these edicts of knowledge-inquiry, and by no means all academics support knowledge-inquiry. Nevertheless it exercises a massive influence over a multitude of aspects of academia: publications, research, funding, education, careers, promotions, interactions with the public. It is the only current conception of rational academic inquiry.

Knowledge-inquiry is, however, profoundly and damagingly irrational. What is so damaging is that the knowledge-inquiry is both massively influential and profoundly irrational.

What do I mean by rationality? The relevant notion is this: there is some, probably rather ill-defined set of rules, strategies or methods which, if put into practice in solving problems or pursuing aims, give us our best chances of success, other things being equal. These rules of reason don't guarantee success. They don't tell you precisely what to do; rather, they indicate what to attempt. They are meta-rules in the sense that they assume that you can already solve many problems, successfully pursue many aims, in the real world (implementing a wide range of methods); the rules of reason tell you how to marshal these past successes so as to give yourself the best chances of solving new problems, of achieving new aims.

Here are four elementary, utterly uncontroversial rules of reason. 
(1) Articulate and seek to improve the articulation of the basic problem(s) to be solved.

(2) Propose and critically assess alternative possible solutions.

(3) When necessary, break up the basic problem to be solved into a number of specialized problems - preliminary, simpler, analogous, subordinate problems - (to be tackled in accordance with rules (1) and (2)), in an attempt to work gradually toward a solution to the basic problem to be solved.

(4) Inter-connect attempts to solve the basic problem and specialized problems, so that basic problem solving may guide, and be guided by, specialized problem solving.

No problem-solving enterprise which persistently violates any one of (1) to (4) can be judged rational. If academia is to contribute to the aim of promoting human welfare, the quality of human life, by intellectual means, in a rational way, in a way that gives the best chances of success, then (1) to (4) must be built into the whole institutional/intellectual structure of academic inquiry.

But knowledge-inquiry violates three of these four most basic rules of reason.

The first point to note is that, granted that academic inquiry has, as its fundamental aim, to help promote human welfare by intellectual and educational means, ${ }^{1}$ then the problems that inquiry fundamentally ought to try to help solve are problems of living, problems of action. From the standpoint of achieving what is of value in life, it is what we $d o$, or refrain from doing, that ultimately matters. Even where new knowledge and technological know-how are relevant to the achievement of what is of value - as it is in medicine or agriculture, for example - it is always what this new knowledge or technological know-how enables us to do that matters. All the global problems discussed above require, for their resolution, not merely new knowledge, but rather new policies, new institutions, new ways of living. Scientific knowledge, and associated technological know-how have, if anything, as we have seen, contributed to the creation of these problems in the first place. Thus problems of living - problems of poverty, illhealth, injustice, deprivation - are solved by what we do, or refrain from doing; they are not solved by the mere provision of some item of knowledge (except when a problem of living is a problem of knowledge).

Second, in order to achieve what is of value in life more successfully than we do at present, we need to discover how to resolve conflicts and problems of living in more cooperatively rational ways than we do at present. There is a spectrum of ways in which conflicts can be resolved, from murder or all out war at the violent end of the spectrum, via enslavement, threat of murder or war, threats of a less extreme kind, manipulation, bargaining, voting, to cooperative rationality at the other end of the spectrum, those involved seeking, by rational means, to arrive at that course of action which does the best justice to the interests of all those involved. A basic task for a kind of academic inquiry that seeks to help promote human welfare must be to discover how conflict resolution can be moved away from the violent end of the spectrum towards the cooperatively rational end.

Granted all this, and granted that the above four rules of reason are put into practice then, at the most fundamental level, academic inquiry needs to:

(1) Articulate, and seek to improve the articulation of, personal, social and global problems of living that need to be solved if the quality of human life is to be enhanced (including those indicated above); 
(2) Propose and critically assess alternative possible solutions - alternative possible actions, policies, political programmes, legislative proposals, ideologies, philosophies of life.

In addition, of course, academic inquiry must:

(3) Break up the basic problems of living into subordinate, specialized problems - in particular, specialized problems of knowledge and technology.

(4) Inter-connect basic and specialized problem solving.

Academic inquiry as it mostly exists at present can be regarded as putting (3) into practice to splendid effect. The intricate maze of specialized disciplines devoted to improving knowledge and technological know-how that go to make up current academic inquiry is the result. But, disastrously, what we have at present, academic inquiry devoted primarily to improving knowledge, fails to put (1), (2) and (4) into practice. In pursuing knowledge, academic inquiry may articulate problems of knowledge, and propose and critically assess possible solutions, possible claims to knowledge - factual theses, observational and experimental results, theories. But, as we have seen, problems of knowledge are not (in general) problems of living; and solutions to problems of knowledge are not (in general) solutions to problems of living. Insofar as academia does at present put (1) and (2) into practice, in departments of social science and policy studies, it does so only at the periphery, and not as its central, fundamental intellectual task.

In short, academic inquiry devoted primarily to the pursuit of knowledge, when construed as having the basic humanitarian aim of helping to enhance the quality of human life by intellectual means, fails to put the two most elementary rules of reason into practice (rules (1) and (2)). Academic inquiry fails to do (at a fundamental level) what it most needs to do, namely (1) articulate problems of living, and (2) propose and critically assess possible solutions. And furthermore, as a result of failing to explore the basic problems that need to be solved, academic inquiry cannot put the fourth rule of rational problem solving into practice either, namely (4) inter-connect basic and specialized problem solving. As I have remarked, three of the four most elementary rules of rational problem solving are violated. (For a more detailed development of this argument see Maxwell, 1980, 1984, 2004.)

This gross structural irrationality of contemporary academic inquiry, of knowledgeinquiry, is no mere formal matter. It has profoundly damaging consequences for humanity. As I have pointed out above, granted that our aim is to contribute to human welfare by intellectual means, the basic problems we need to discover how to solve are problems of living, problems of action, not problems of knowledge. In failing to give intellectual priority to problems of living, knowledge-inquiry fails to tackle what most needs to be tackled in order to contribute to human welfare. In devoting itself to acquiring knowledge in a way that is unrelated to sustained concern about what humanity's most urgent problems are, as a result of failing to put (1) and (2) into practice, and thus failing to put (4) into practice as well, the danger is that scientific and technological research will respond to the interests of the powerful and the wealthy, rather than to the interests of the poor, of those most in need. Scientists, officially seeking knowledge of truth per se, have no official grounds for objecting if those who fund research - governments and industry - decide that the truth to be sought will reflect their interests, rather than the interests of the world's poor. And priorities of 
scientific research, globally, do indeed reflect the interests of the first world, rather than those of the third world. ${ }^{2}$

Knowledge and technology successfully pursued in a way that is not rationally subordinated to the tackling of more fundamental problems of living, through the failure to put (1), (2) and (4) into practice, is bound to lead to the kind of global problems discussed above, problems that arise as a result of newly acquired powers to act being divorced from the ability to act wisely. The creation of our current global problems, and our inability to respond adequately to these problems, has much to do, in other words, with the long-standing, rarely noticed, structural irrationality of our institutions and traditions of learning, devoted as they are to acquiring knowledge dissociated from learning how to tackle our problems of living in more cooperatively rational ways. Knowledge-inquiry, because of its irrationality, is designed to intensify, not help solve, our current global problems. ${ }^{3}$

\section{Wisdom-Inquiry}

Inquiry devoted primarily to the pursuit of knowledge is, then, grossly and damagingly irrational when judged from the standpoint of contributing to human welfare by intellectual means. At once the question arises: What would a kind of inquiry be like that is devoted, in a genuinely rational way, to promoting human welfare by intellectual means? I shall call such a hypothetical kind of inquiry wisdom-inquiry, to stand in contrast to knowledge-inquiry.

As a first step at characterizing wisdom-inquiry, we may take knowledge-inquiry (at its best) and modify it just sufficiently to ensure that all four elementary rules of rational problem-solving, indicated above, are built into its intellectual and institutional structure: see Figure 1.

The primary change that needs to be made is to ensure that academic inquiry implements rules (1) and (2). It becomes the fundamental task of social inquiry and the humanities (1) to articulate, and seek to improve the articulation of, our problems of living, and (2) to propose and critically assess possible solutions, from the standpoint of their practicality and desirability. In particular, social inquiry has the task of discovering how conflicts may be resolved in less violent, more cooperatively rational ways. It also has the task of promoting such tackling of problems of living in the social world beyond academe. Social inquiry is, thus, not primarily social science, nor, primarily, concerned to acquire knowledge of the social world; its primary task is to promote more cooperatively rational tackling of problems of living in the social world. Pursued in this way, social inquiry is intellectually more fundamental than the natural and technological sciences, which tackle subordinate problems of knowledge, understanding and technology, in accordance with rule (3). In Figure 1, implementation of rule (3) is represented by the specialized problem solving of the natural, technological and formal sciences, and more specialized aspects of social inquiry and the humanities. Rule (4) is represented by the two-way arrows linking fundamental and specialized problem solving, each influencing the other.

One can go further. According to this view, the thinking that we engage in as we live, in seeking to realize what is of value to us, is intellectually more fundamental than the whole of academic inquiry (which has, as its basic purpose, to help cooperatively rational thinking and problem solving in life to flourish). Academic thought emerges as a kind of specialization of personal and social thinking in life, the result of implementing rule (3); this means there needs to be a two-way interplay of ideas, arguments and experiences between the social world and academia, in accordance with 
rule (4). This is represented, in figure 1, by the two-way arrows linking academic inquiry and the social world.

The natural and technological sciences need to recognize three domains of discussion: evidence, theory, and aims. Discussion of aims seeks to identify that highly problematic region of overlap between that which is discoverable, and that which it is of value to discover. Discussion of what it is of value to discover interacts with social inquiry, in accordance with rule (4).

It may be asked: but if academic inquiry today really does suffer from the wholesale structural irrationality just indicated, when and how did this come about? I turn now to a consideration of that question. The answer leads to an improved version of wisdominquiry, and to a new argument in support of my claim that wisdom-inquiry, potentially, is more rigorous and of greater human value, than knowledge-inquiry.

\section{The Traditional Enlightenment}

The irrationality of contemporary academic inquiry has its roots in blunders made by the philosophes of the 18th century Enlightenment.

A basic idea of the Enlightenment, perhaps the basic idea, was to try to learn from scientific progress how to go about making social progress towards an enlightened world. The philosophes, Voltaire, Diderot, Condorcet and others, did what they could to put this immensely important idea into practice, in their lives. They fought 


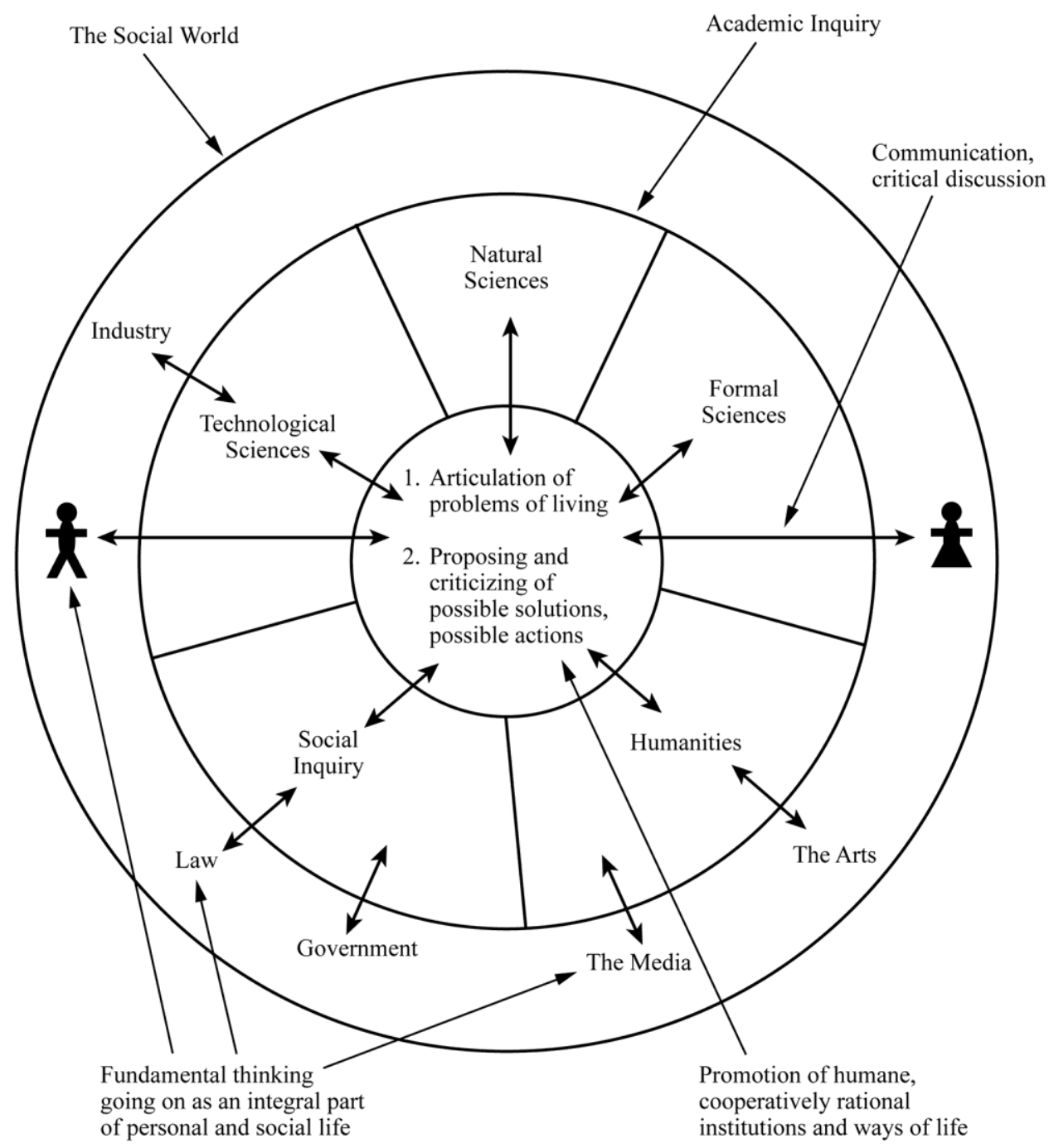

Figure 1: Wisdom-Inquiry Implementing Problem-Solving Rationality

dictatorial power, superstition, and injustice with weapons no more lethal than those of argument and wit. They gave their support to the virtues of tolerance, openness to doubt, readiness to learn from criticism and from experience. Courageously and energetically they laboured to promote rationality in personal and social life (Gay, 1973).

Unfortunately, in developing the Enlightenment idea intellectually, the philosophes blundered. They thought the task was to develop the social sciences alongside the natural sciences. I shall call this the traditional Enlightenment Programme. It was developed throughout the 19th century, by Comte, Marx, Mill and others, and built into the institutional structure of universities during the 20th century, with the creation of departments of social science (see Aron, 1968, 1970; Farganis, 1993, Introduction; Hayek, 1979). Knowledge-inquiry, as we have it today, by and large, is the result, both natural science and social inquiry being devoted, in the first instance, to the pursuit of knowledge.

But, from the standpoint of creating a kind of inquiry designed to help humanity learn how to become civilized, all this amounts to a series of monumental blunders. These blunders are at the root of the damaging irrationality of current academic inquiry. 


\section{The New Enlightenment}

In order to implement properly the basic Enlightenment idea of learning from scientific progress how to achieve social progress towards a civilized world, it is essential to get the following three steps right.

1. The progress-achieving methods of science need to be correctly identified.

2. These methods need to be correctly generalized so that they become fruitfully applicable to any human endeavour, whatever the aims may be, and not just applicable to the endeavour of improving knowledge.

3. The correctly generalized progress-achieving methods then need to be exploited correctly in the great human endeavour of trying to make social progress towards an enlightened, wise, civilized world.

Unfortunately, the philosophes of the Enlightenment got all three points wrong. And as a result these blunders, undetected and uncorrected, are built into the intellectualinstitutional structure of academia as it exists today. ${ }^{4}$

First, the philosophes failed to capture correctly the progress-achieving methods of natural science. From D'Alembert in the $18^{\text {th }}$ century to Popper in the $20^{\text {th }}$ (Popper, 1963), the widely held view, amongst both scientists and philosophers, has been (and continues to be) that science proceeds by assessing theories impartially in the light of evidence, no permanent assumption being accepted by science about the universe independently of evidence. But this standard empiricist view is untenable. Two considerations govern acceptance of theories in physics: empirical success and unity. But in persistently accepting unified theories, to the extent of rejecting disunified rivals that are just as, or even more, empirically successful, physics makes a big persistent assumption about the universe. The universe is such that all disunified theories are false. It has some kind of unified dynamic structure. It is physically comprehensible in the sense that explanations for phenomena exist to be discovered.

But this untestable (and thus metaphysical) assumption that the universe is comprehensible is profoundly problematic. Science is obliged to assume, but does not know, that the universe is comprehensible. Much less does it know that the universe is comprehensible in this or that way. A glance at the history of physics reveals that ideas have changed dramatically over time.

The way to overcome this fundamental dilemma inherent in the scientific enterprise is to construe physics as making a hierarchy of metaphysical assumptions concerning the comprehensibility and knowability of the universe, these assumptions asserting less and less as one goes up the hierarchy, and thus becoming more and more likely to be true: see figure 2. In this way a framework of relatively insubstantial, unproblematic, fixed assumptions and associated methods is created within which much more substantial and problematic assumptions and associated methods can be changed, and indeed improved, as scientific knowledge improves. Put another way, a framework of relatively unspecific, unproblematic, fixed aims and methods is created within which much more specific and problematic aims and methods evolve as scientific knowledge evolves. (A basic aim of science is to discover in what precise way the universe is comprehensible, this aim evolving as assumptions about comprehensibility evolve.) There is positive feedback between improving knowledge, and improving aims-and- 


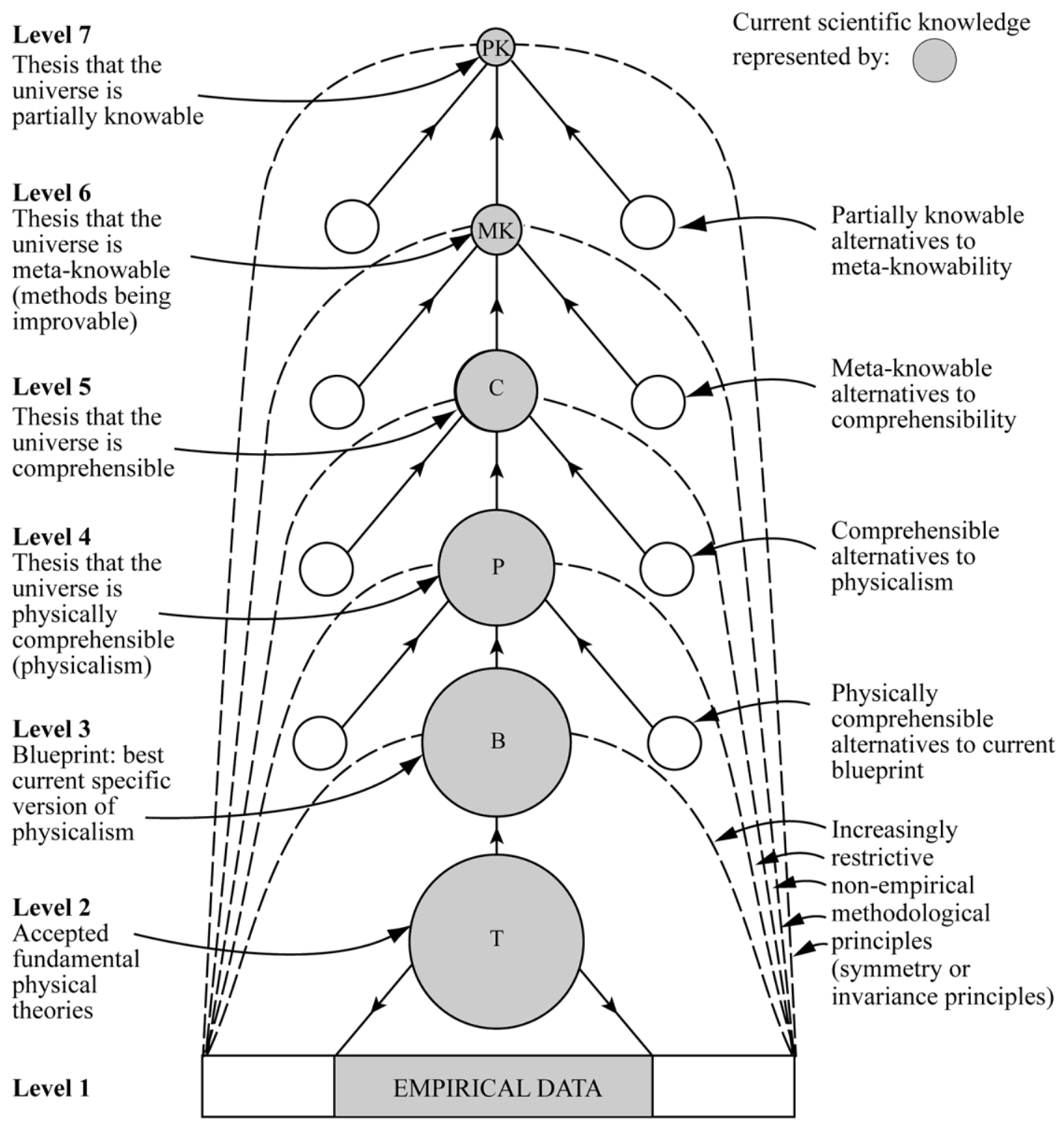

Figure 2: Hierarchical Conception of Science

methods, improving knowledge-about-how-to-improve-knowledge. This is the nub of scientific rationality, the methodological key to the unprecedented success of science. ${ }^{5}$ Science adapts its nature to what it discovers about the nature of the universe (see Maxwell, 1974, 1976, 1984, 1998, 2004, 2005, 2017a, 2017b).

So much for the first blunder of the traditional Enlightenment, and how to put it right.

Second, having failed to identify the methods of science correctly, the philosophes naturally failed to generalize these methods properly. They failed to appreciate that the idea of representing the problematic aims (and associated methods) of science in the form of a hierarchy can be generalized and applied fruitfully to other worthwhile enterprises besides science. Many other enterprises have problematic aims problematic because aims conflict, and because what we seek may be unrealizable, undesirable, or both. Such enterprises, with problematic aims, would benefit from employing a hierarchical methodology, generalized from that of science, thus making it possible to improve aims and methods as the enterprise proceeds. There is the hope that, as a result of exploiting in life methods generalized from those employed with 
such success in science, some of the astonishing success of science might be exported into other worthwhile human endeavours, with problematic aims quite different from those of science.

Third, and most disastrously of all, the philosophes failed completely to try to apply such generalized, hierarchical progress-achieving methods to the immense, and profoundly problematic enterprise of making social progress towards an enlightened, wise world. The aim of such an enterprise is notoriously problematic. For all sorts of reasons, what constitutes a good world, an enlightened, wise or civilized world, attainable and genuinely desirable, must be inherently and permanently problematic. ${ }^{6}$ Here, above all, it is essential to employ the generalized version of the hierarchical, progress-achieving methods of science, designed specifically to facilitate progress when basic aims are problematic: see Figure 3. It is just this that the philosophes failed to do. Instead of applying the hierarchical methodology to social life, the philosophes sought to apply a seriously defective conception of scientific method to social science, to the task of making progress towards, not a better world, but to better knowledge of social phenomena. And this ancient blunder is still built into the institutional and intellectual structure of academia today, inherent in the current character of social science (Maxwell, 1984, chapters 3, 6 and 7; 2014).

Properly implemented, in short, the Enlightenment idea of learning from scientific progress how to achieve social progress towards an enlightened world would involve developing social inquiry, not as social science, but as social methodology, or social philosophy. A basic task would be to get into personal and social life, and into other institutions besides that of science - into government, industry, agriculture, commerce, the media, law, education, international relations - hierarchical, progress-achieving methods (designed to improve problematic aims) arrived at by generalizing the methods of science. A basic task for academic inquiry as a whole would be to help humanity learn how to resolve its conflicts and problems of living in more just, cooperatively rational ways than at present. This task would be intellectually more fundamental than the scientific task of acquiring knowledge. Social inquiry would be intellectually more fundamental than physics. As I have already remarked, academia would be a kind of people's civil service, doing openly for the public what actual civil services are supposed to do in secret for governments. Academia would have just sufficient power (but no more) to retain its independence from government, industry, the press, public opinion, and other centres of power and influence in the social world. It would seek to learn from, educate, and argue with the great social world beyond, but would not dictate. Academic thought would be pursued as a specialized, subordinate part of what is really important and fundamental: the thinking that goes on, individually, socially and institutionally, in the social world, guiding individual, social and institutional actions and life. The fundamental intellectual and humanitarian aim of inquiry would be to help humanity acquire wisdom - wisdom being the capacity to realize (apprehend and create) what is of value in life, for oneself and others, wisdom thus including knowledge and technological know-how but much else besides.

One outcome of getting into social and institutional life the kind of aim-evolving, hierarchical methodology indicated above, generalized from science, is that it becomes possible for us to develop and assess rival philosophies of life as a part of social life, somewhat as theories are developed and assessed within science. Such a hierarchical methodology provides a framework within which competing views about what our aims and methods in life should be - competing religious, political and moral views - may be cooperatively assessed and tested against broadly agreed, unspecific aims (high up in the hierarchy of aims) and the experience of personal and social life. There is the possibility 
of cooperatively and progressively improving such philosophies of life (views about what is of value in life and how it is to be achieved) much as theories are cooperatively and progressively improved in science. In science, ideally, theories are critically assessed with respect to each other, with respect to metaphysical ideas concerning the comprehensibility of the universe, and with respect to experience (observational and experimental results). In a somewhat analogous way, diverse philosophies of life may be critically assessed with respect to each other, with respect to relatively uncontroversial, agreed ideas about aims and what is of value, and with respect to experience - what we do, achieve, fail to achieve, enjoy and suffer - the aim being to improve philosophies of life (and more specific philosophies of more specific enterprises within life such as government, education or art) so that they offer greater help with the realization of what is of value in life. This hierarchical methodology is especially relevant to the task of resolving conflicts about aims and ideals, as it helps disentangle agreement (high up in the hierarchy) and disagreement (more likely to be low down in the hierarchy).

Wisdom-inquiry, because of its greater rigour, has intellectual standards that are, in important respects, different from those of knowledge-inquiry. Whereas knowledgeinquiry demands that emotions and desires, values, human ideals and aspirations, philosophies of life be excluded from the intellectual domain of inquiry, wisdominquiry requires that they be included. In order to discover what is of value in life it is essential that we attend to our feelings and desires. But not everything we desire is desirable, and not everything that feels good is good. Feelings, desires and values need to be subjected to critical scrutiny. And of course feelings, desires and values must not be permitted to influence judgements of factual truth and falsity. Wisdom-inquiry embodies a synthesis of traditional rationalism and romanticism. It includes elements from both, and it improves on both. It incorporates romantic ideals of integrity, having to do with motivational and emotional honesty, honesty about desires and aims; and at the same time it incorporates traditional rationalist ideals of integrity, having to do with respect for objective fact, knowledge, and valid argument. Traditional rationalism takes its inspiration from science and method; romanticism takes its inspiration from art, from imagination, and from passion. Wisdom-inquiry holds art to have a fundamental rational role in inquiry, in revealing what is of value, and unmasking false values; but science, too, is of fundamental importance. What we need, for wisdom, is an interplay of sceptical rationality and emotion, an interplay of mind and heart, so that we may develop mindful hearts and heartfelt minds. It is time we healed the great rift in our culture, so graphically depicted by Snow (1986).

All in all, if the Enlightenment revolution had been carried through properly, the three steps indicated above being correctly implemented, the outcome would have been a kind of academic inquiry very different from what we have at present, inquiry devoted primarily to the intellectual aim of acquiring knowledge.

\section{Cultural Implications of Wisdom-Inquiry}

Wisdom-inquiry does not just do better justice to the social or practical dimension of inquiry than knowledge-inquiry; it does better justice to the "intellectual" or "cultural" aspects as well. Here, what really matters is the desire that people have to see, to know, to understand, the passionate curiosity that individuals have about aspects of the world, and the knowledge and understanding that people acquire and share as a result of actively following up their curiosity. An important task for academic thought in universities is to encourage non-professional thought to flourish outside universities. As Einstein once remarked "Knowledge exists in two forms - lifeless, stored in books, and alive in the consciousness of men. The second form of existence is after all the 


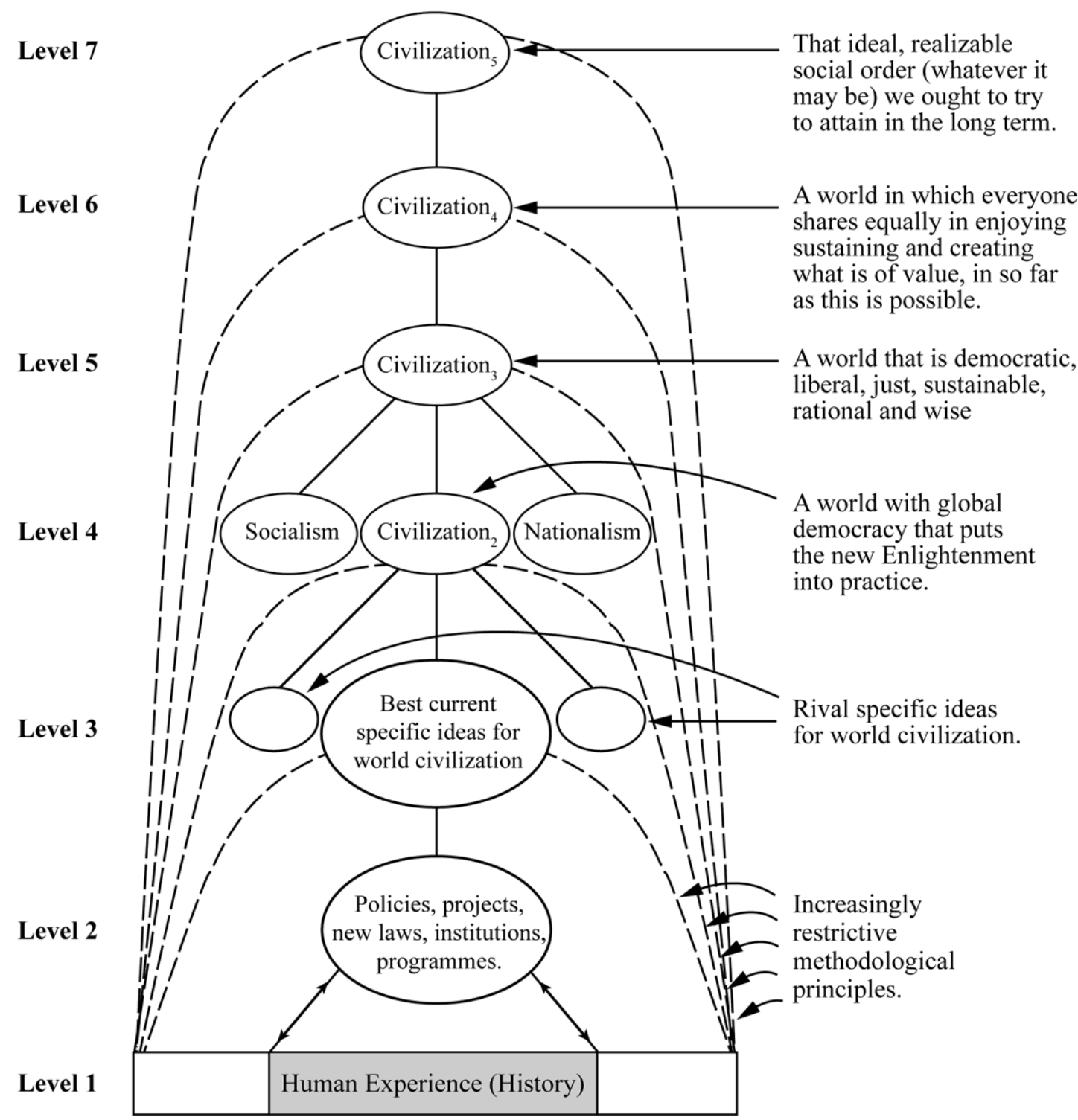

Figure 3: Hierarchical Social Methodology Generalized from Science

essential one; the first, indispensable as it may be, occupies only an inferior position." (Einstein, 1973, p. 80).

Wisdom-inquiry is designed to promote all this in a number of ways. It does so as a result of holding thought, at its most fundamental, to be the personal thinking we engage in as we live. It does so by recognizing that acquiring knowledge and understanding involves articulating and solving personal problems that one encounters in seeking to know and understand. It does so by recognizing that passion, emotion and desire, have a rational role to play in inquiry, disinterested research being a myth. Again, as Einstein has put it "The most beautiful experience we can have is the mysterious. It is the fundamental emotion which stands at the cradle of true art and true science. Whoever does not know it and can no longer wonder, no longer marvel, is as good as dead, and his eyes are dimmed." (Einstein, 1973, p. 11).

Knowledge-inquiry, by contrast, all too often fails to nourish "the holy curiosity of inquiry" (Einstein, 1949, p. 17), and may even crush it out altogether. Knowledgeinquiry gives no rational role to emotion and desire; passionate curiosity, a sense of 
mystery, of wonder, have no place, officially, within the rational pursuit of knowledge. The intellectual domain becomes impersonal and split off from personal feelings and desires; it is difficult for "holy curiosity" to flourish in such circumstances.

Knowledge-inquiry hardly encourages the view that inquiry at its most fundamental is the thinking that goes on as a part of life; on the contrary, it upholds the idea that fundamental research is highly esoteric, conducted by physicists in contexts remote from ordinary life. Even though the aim of inquiry may, officially, be human knowledge, the personal and social dimension of this is all too easily lost sight of, and progress in knowledge is conceived of in impersonal terms, stored lifelessly in books and journals. Rare is it for popular books on science to take seriously the task of exploring the fundamental problems of a science in as accessible, non-technical and intellectually responsible a way as possible. ${ }^{7}$ Such work is not highly regarded by knowledge-inquiry, as it does not contribute to "expert knowledge". The failure of knowledge-inquiry to take seriously the highly problematic nature of the aims of inquiry leads to insensitivity as to what aims are being pursued, to a kind of institutional hypocrisy. Officially, knowledge is being sought "for its own sake", but actually the goal may be immortality, fame, the flourishing of one's career or research group, as the existence of bitter priority disputes in science indicates. Education suffers. Science students are taught a mass of established scientific knowledge, but may not be informed of the problems which gave rise to this knowledge, the problems which scientists grappled with in creating the knowledge. Even more rarely are students encouraged themselves to grapple with such problems. And rare, too, is it for students to be encouraged to articulate their own problems of understanding that must, inevitably arise in absorbing all this information, or to articulate their instinctive criticisms of the received body of knowledge. All this tends to reduce education to a kind of intellectual indoctrination, and serves to kill "holy curiosity". ${ }^{8}$ Officially, courses in universities divide up into those that are vocational, like engineering, medicine and law, and those that are purely educational, like physics, philosophy or history. What is not noticed, again through insensitivity to problematic aims, is that the supposedly purely educational are actually vocational as well: the student is being trained to be an academic physicist, philosopher or historian, even though only a minute percentage of the students will go on to become academics. Real education, which must be openended, and without any pre-determined goal, rarely exists in universities, and yet few notice. (These considerations are developed further in Maxwell, 1976, 1984 and 2004.)

In order to enhance our understanding of persons as beings of value, potentially and actually, we need to understand them empathetically, by putting ourselves imaginatively into their shoes, and experiencing, in imagination, what they feel, think, desire, fear, plan, see, love and hate. For wisdom-inquiry, this kind of empathic understanding is rational and intellectually fundamental. Articulating problems of living, and proposing and assessing possible solutions is, we have seen, the fundamental intellectual activity of wisdom-inquiry. But it is just this that we need to do to acquire empathic understanding. Social inquiry, in tackling problems of living, is also promoting empathic understanding of people. Empathic understanding is essential to wisdom. Elsewhere I have argued, indeed, that empathic understanding plays an essential role in the evolution of consciousness. It is required for cooperative action, and even for science. (For a fuller exposition of such an account of empathic understanding see Maxwell, 1984, pp. 171-189 and chapter 10; and 2001, chapters 5-7 and 9).

Granted knowledge-inquiry, on the other hand, empathic understanding hardly satisfies basic requirements for being an intellectually legitimate kind of explanation 
and understanding (Maxwell, 1984, pp. 183-185). It has the status merely of "folk psychology", on a par with "folk physics".

\section{Conclusion}

Humanity is in deep trouble. We urgently need to learn how to make progress towards a wiser, more civilized world. This in turn requires that we possess traditions and institutions of learning rationally designed - well designed - to help us achieve this end. It is just this that we do not have at present. What we have instead is natural science and, more broadly, inquiry devoted to acquiring knowledge. Judged from the standpoint of helping us create a better world, knowledge-inquiry of this type is dangerously and damagingly irrational. We need to bring about a major intellectual and institutional revolution in the aims and methods of inquiry, from knowledge-inquiry to wisdom-inquiry. Almost every branch and aspect of academic inquiry needs to change.

A basic intellectual task of academic inquiry would be to articulate our problems of living (personal, social and global) and propose and critically assess possible solutions, possible actions. This would be the task of social inquiry and the humanities. Tackling problems of knowledge would be secondary. Social inquiry would be at the heart of the academic enterprise, intellectually more fundamental than natural science. On a rather more long-term basis, social inquiry would be concerned to help humanity build hierarchical methods of problem-solving into the fabric of social and political life so that we may gradually acquire the capacity to resolve our conflicts and problems of living in more cooperatively rational ways than at present. Natural science would change to include three domains of discussion: evidence, theory, and aims - the latter including discussion of metaphysics, values and politics. Academia would actively seek to educate the public by means of discussion and debate, and would not just study the public.

This revolution - intellectual, institutional and cultural - if it ever comes about, would be comparable in its long-term impact to that of the Renaissance, the scientific revolution, or the Enlightenment. The outcome would be traditions and institutions of learning rationally designed to help us acquire wisdom. There are a few scattered signs that this intellectual revolution, from knowledge to wisdom, is already under way. It will need, however, much wider cooperative support - from scientists, scholars, students, research councils, university administrators, vice chancellors, teachers, the media and the general public - if it is to become anything more than what it is at present, a fragmentary and often impotent movement of protest and opposition, often at odds with itself, exercising little influence on the main body of academic work. I can hardly imagine any more important work for anyone associated with academia than, in teaching, learning and research, to help promote this revolution.

\section{References}

Aron, R. 1968, Main Currents in Sociological Thought, Penguin, Harmondsworth, vol. 1 1968; vol. 2, 1970.

Berlin, I., 1980, Against the Current, Hogarth Press, London.

Einstein, A., 1949, "Autobiographical Notes", in P. A. Schilpp, ed. Albert Einstein: Philosopher-Scientist, Open Court, Illinois, pp. 3-94. 1973, Ideas and Opinions, Souvenir Press, London.

Farganis, J. (ed.), 1993, Readings in Social Theory: The classic Tradition to PostModernism, McGraw-Hill, New York.

Gay, P., 1973, The Enlightenment: An Interpretation, Wildwood House, London. 
Hayek, F. A., 1979, The Counter-Revolution of Science, 1979, LibertyPress, Indianapolis. Laing, R. D., 1965, The Divided Self, 1965, Penguin, Harmondsworth.

Langley, C., 2005, Soldiers in the Laboratory, Scientists for Global Responsibility, Folkstone.

Maxwell, N., 1974, 'The Rationality of Scientific Discovery', Philosophy of Science 41, pp. 123-53 and 247-95.

, 1976, What's Wrong With Science?, Bran's Head Books, Frome, England. 1980, 'Science, Reason, Knowledge and Wisdom: A Critique of Specialism', Inquiry 23, pp. 19-81.

1984, From Knowledge to Wisdom, Blackwell, Oxford (2nd ed., 2007, Pentire

Press, London).

, 1998, The Comprehensibility of the Universe (Oxford University Press,

Oxford, pbk. 2003).

, 2001, The Human World in the Physical Universe, Rowman and

Littlefield, Lanham, Maryland.

, 2004, Is Science Neurotic?, Imperial College Press, London.

2005, 'Popper, Kuhn, Lakatos and Aim-Oriented Empiricism', Philosophia

32, pp. 181-239.

Exeter).

2014, How Universities Can Help Create a Wiser World (Imprint Academic,

,2017a, In Praise of Natural Philosophy: A Revolution for Thought and Life,

McGill-Queen's University Press, Montreal.

, 2017b, Understanding Scientific Progress, Paragon House, Saint Paul,

Minnesota.

Penrose, R., 2004, The Road to Reality, Jonathan Cape, London.

Popper, K. R., 1959, The Logic of Scientific Discovery, Hutchinson, London.

1961, The Poverty of Historicism, Routledge and Kegan Paul, London.

1962, The Open Society and Its Enemies, Routledge and Kegan Paul, London. 1963, Conjectures and Refutations, Routledge and Kegan Paul, London.

Smith, D., 2003, The Atlas of War and Peace, Earthscan, London.

Snow, C. P., 1986, The Two Cultures: And a Second Look, Cambridge University Press, Cambridge.

\section{Notes}

${ }^{1}$ This assumption may be challenged. Does not academic inquiry seek knowledge for its own sake - it may be asked - whether it helps promote human welfare or not? Later on, I will argue that the conception of inquiry I am arguing for, wisdom-inquiry, does better justice than knowledge-inquiry to both aspects of inquiry, pure and applied. The basic aim of inquiry, according to wisdom-inquiry, is to help us realize what is of value in life, "realize" meaning both "apprehend" and "make real". "Realize" thus accommodates both aspects of inquiry, "pure" research or "knowledge pursued for its own sake" on the one hand, and technological or "mission-oriented" research on the other - both, ideally, seeking to contribute to what is of value in human life. Wisdominquiry, like sight, is there to help us find our way around. And like sight, wisdominquiry is of value to us in two ways: for its intrinsic value, and for practical purposes. The first is almost more precious than the second.

${ }^{2}$ Funds devoted, in the USA, UK and some other wealthy countries, to military research are especially disturbing: see Langley (2005) and Smith (2003).

${ }^{3}$ See Maxwell (1984, chapter 3) for a much more detailed discussion of the damaging 
social repercussions of knowledge-inquiry.

${ }^{4}$ The blunders of the philosophes are not entirely undetected. Karl Popper, in his first four works, makes substantial improvements to the traditional Enlightenment programme (although Popper does not himself present his work in this fashion). Popper first improves traditional conceptions of the progress-achieving methods of science (Popper, 1959). This conception, falsificationism, is then generalized to become critical rationalism. This is then applied to social, political and philosophical problems (Popper, 1961, 1962, 1963). The version of the Enlightenment programme about to be outlined here can be regarded as a radical improvement of Popper's version: see Maxwell (2004, chapter 3).

${ }^{5}$ Natural science has made such astonishing progress in improving knowledge and understanding of nature because it has put something like the hierarchical methodology, indicated here, into scientific practice. Officially, however, scientists continue to hold the standard empiricist view that no untestable metaphysical theses concerning the comprehensibility and knowability of the universe are accepted as a part of scientific knowledge. As I have argued elsewhere (Maxwell, 2004, chapter 2), science would be even more successful, in a number of ways, if scientists adopted and explicitly implemented the hierarchical methodology indicated here.

${ }^{6}$ There are a number of ways of highlighting the inherently problematic character of the aim of creating civilization. People have very different ideas as to what does constitute civilization. Most views about what constitutes Utopia, an ideally civilized society, have been unrealizable and profoundly undesirable. People's interests, values and ideals clash. Even values that, one may hold, ought to be a part of civilization may clash. Thus freedom and equality, even though inter-related, may nevertheless clash. It would be an odd notion of individual freedom which held that freedom was for some, and not for others; and yet if equality is pursued too singlemindedly this will undermine individual freedom, and will even undermine equality, in that a privileged class will be required to enforce equality on the rest, as in the old Soviet Union. A basic aim of legislation for civilization, we may well hold, ought to be increase freedom by restricting it: this brings out the inherently problematic, paradoxical character of the aim of achieving civilization. One thinker who has stressed the inherently problematic, contradictory character of the idea of civilization is Isaiah Berlin; see, for example, Berlin (1980, pp. 74-79). Berlin thought the problem could not be solved; I, on the contrary, hold that the hierarchical methodology indicated here provides us with the means to learn how to improve our solution to it in real life.

${ }^{7}$ A recent, remarkable exception is Penrose (2004).

${ }^{8}$ I might add that the hierarchical conception of science indicated here does better justice to the scientific quest for understanding than does orthodox standard empiricist views: see Maxwell (1998, chapters 4 and 8; 2004, chapter 2).

Submitted to On The Horizon

Manuscript ID OTH-04-2016-0019

Title Can Universities Save Us From Disaster?

Authors Maxwell, Nicholas

Date Submitted 26-Apr-2016 